\title{
JUSTICIA EQUITATIVA y Justicia Ética
}

\author{
Por: Aída Sotelo Céspedes*

\section{Resumen} \\ La ética surgida de la clínica psicoanalítica permite explorar \\ conflictos sociales, con una orientación que implica reconocer \\ que la responsabilidad es distinta para cada uno, pero la verdad \\ del ser singular del sujeto es difícil de reconocer, es una verdad \\ vital para el colectivo, aunque no lo evidencien y permanezca \\ como 'lo in-sabido' de sí por el sujeto mismo. Este trabajo \\ recuerda los aspectos libidinales que originan el deseo de justicia \\ y explica cómo los lazos sociales dependen de asumir la propia \\ alteridad y la falta, en tanto, el ser es "lo otro" del sujeto, es decir, \\ su propia e inédita manera de goce, lo cual le imprime identidad, \\ pero a la vez le priva de compañía, introduce una carencia y la \\ insuficiencia del lenguaje para ordenar toda la existencia: la falta \\ fundamental que afecta al Otro y al sujeto.
}

\section{Palabras Claves}

Ser, Real, Identificación, Yo, Alteridad, Sujeto, Libidinal, Imposible

\section{EQUALJUSTICEANDETHICALJUSTICE}

\section{*Perfil}

Bogotana, psicoanalista, escritora, docente universitaria, dibujante y médica cirujana.

Estudios de psicoanálisis en Université Paris VIII à Saint Denis y en L'École de la cause freudienne de Paris y Medicina en la Universidad Nacional de Colombia.

Docente en las universidades Nacional de Colombia, Pedagógica Nacional, Distrital "Francisco José de Caldas", Pontificia Javeriana, Universidad Central, Antonio Nariño y UNIMINUTO.

Distinciones literarias: "Cortesía" Cuento finalista en el Premio Nacional de cuento breve de Samaná, 2001. "Amnesia" Novela finalista en el Primer concurso internacional de novela breve "Álvaro Cepeda Samudio", 2003. "Reflejos" Poemario finalista en el concurso nacional de poesía del ministerio de cultura 2005.

\begin{abstract}
The ethics emerged from the psychoanalytical clinic allows to explore social conflicts, with an orientation that implies to contemplate that the responsibility is different for each one. However, the reality of being singular of the subject is difficult to consider. It is a vital reality for the mass, although it is not apparent to them and remains as "lo in-sabido" by the subject itself. This work reminds the reader of the aspects of "libidinales" that originate the desire of justice and explains how the social ties depend in assuming the self "alteridad" and the deficiency. Self is the other of the subject, such as, the self and original way to be. This signifies identity, but at the same time it does not allow any companionship, it introduces a deficiency and the insufficient of the language to arrange all of the existence; the fundamental shortage that affects the other and the subject.
\end{abstract}

The ethical justice was not based in the equal distribution of having, but, in the reason that it admits the "alteridad", the deficiency and the impossible.

\section{Key Words}

To be, Real, Identification, Me, "Alteridad", Subject, "Libidinal", Impossible

Recibido, 25 de mayo de 2007; aprobado, 15 de junio de 2007 
a justicia ética no está basada en la distribución igualitaria del tener, sino en el juicio que logra admitir la alteridad, la carencia y lo imposible.

La ética surgida de la clínica psicoanalítica permite explorar conflictos sociales, que implican reconocer la verdad como el ser singular del sujeto, él es vital para el colectivo. Este trabajo pretende explicar cómo el ser siempre es "el otro" y cómo a eso apunta la palabra de Cristo.

En primer lugar, es necesario resaltar que la responsabilidad nunca es colectiva, incluso cuando se emprende una acción en grupo, la responsabilidad es distinta para cada uno. En cambio, las consecuencias del acto siempre son sociales. La palabra o la reflexión se manifiestan fuera de quien lo dice o lo piensa y eso, no puede, ni debe estar supuesto de antemano por leyes o normas. Por eso es pertinente la ética porque, en ocasiones, la irresponsabilidad se puede camuflar en la legalidad o porque la aplicación de la ley puede ser injusta. Alejandro Dumas lo reiteró con sus obras, principalmente en Los miserables. Por tanto, normas o códigos morales no bastan para definir la ética. La ética surge como la elección del juicio ante la norma.

Un grupo, tribal o global, brinda camuflajes con los que el sujeto evita afrontar su deber, por lo cual, defender las diferencias o los intereses de un grupo, puede ser legítimo pero, sólo puede hablarse de ética (no de derecho), cuando un sujeto preserva al otro, salva la alteridad, incluso contra su propio beneficio o contra lo legal.

La vida de sujeto es su ser, al cual la palabra señala, pero cuya verdad no alcanza a recubrir. Sin embargo, algo de la verdad se encarna en lenguaje, como dice la frase bíblica: "Y el verbo se hizo carne". Freud, encontró eso en su clínica y llamó Umwebusste (lo in-sabido, mal traducido "inconsciente") a una verdad que el sujeto no sabe aunque le concierne. Esa verdad habla, pero con un lenguaje cifrado, esa verdad se hace carne en los síntomas. Y Freud vio que el sujeto puede librarse del sufrimiento por la palabra, cuando ésta es proferida desde el lugar de su verdad. Esa verdad vale por la vida misma, pues le da un sentido, que no es el de la existencia biológica y homogenizada en la masa, por eso no se logra en la legalidad farisea. Pero, si hay dos vidas, también hay dos muertes, en el intervalo "entre" éstas, se sitúa la ley ex-nihilo que guió a Antígona para enfrentar a Creónte y las leyes de Tebas ${ }^{1}$. Allí surge la elección ética.

\section{OPCIÓN POR LA VERDAD DELSER}

La vida singular exige hacerse responsable: aceptar que no hay goce completo en el mundo y reconocer la falta propia (a esto Freud lo llamó "aceptar la castración"). Pero con esa falta, que es su "verdad", el sujeto podría crear y, así, renovar lo instituido. La "buena nueva" es que a partir de su ser defectuoso, el sujeto puede hacerse digno. Cristo, el sujeto ético, supo el alto precio a pagary también que en esa realización el hombre está solo, no puede apelar la ayuda de nadie, por eso se aparta para hacer su decisión y la anuncia en la oración del Monte de los Olivos.

Se ve ahí, que la ética es la dimensión del acto sin Otro, sin la orientación de ley alguna en el lenguaje. El sujeto ético la afronta, como Cristo. Agamben en su texto Sin rango, cita al De hominis dignitate de Pico de la Mirandola: "el hombre, al haber sido plasmado cuando se habían agotado los modelos de la creación, no puede tener ni arquetipo, ni lugar propio, ni rango específico" ${ }^{2}$. Entonces, si lo que define al hombre no es una sustancia positiva, por su ausencia de dignitas ${ }^{3}$, el ser hablante está conminado a elegir su dignidad, a constituirla en acto. Sólo el ser hablante enfrenta la dimensión del acto, su libertad es la de modificar el sentido de su ser con su palabra en acto, se determina en "el siendo" continuo que es su inconsciente.

Lo duro de esta tarea -que vale por la vida misma- es que enfrentar esa verdad implica la

1 Cf. Lacan, J. (1985) L'étique de la psychanalyse, Le sèminaire, livre VII, París: Éditions du Seuil, pp. 315.

2 Agamben, G. (2005) "Sin rango", Lo abierto, El hombre y el animal, Valencia: Pre-textos, p. 43.

3 En el texto dignitas significa rango. 
soledad de ser único. Es lo inadmisible, desde la perspectiva de lo 'común', por eso no es ninguna verdad absoluta. La verdad que encontró Freud en su clínica es parcial, singular y concierne al ser, por tanto, no puede ser dicha sino a medias, porque el significante fracasa al intentar dar cuenta de ese ser; en contrapartida, el ser es propio de manera irrefutable.

Como el saber (lenguaje) no atrapa la verdad del ser, éste es un enigma, de allí la frase de Cristo: "Yo soy el camino, la verdad y la vida". En mi interpretación laica de esta frase no pongo el énfasis en el "yo" [moi], en la persona, que es una máscara ${ }^{4}$; sino en el sujeto [je] que subyace al "soy" [je suis]..$^{5}$ El ser no se "dice", sin embargo, por el camino de la palabra algo de su verdad se devela ${ }^{6}$, esa es la vida que vale la pena. El ser es la clave, Jesús no invita a copiar su fórmula, indica que hay que develar el ser propio, en esa tarea se condensan "camino, verdad y vida".

"La clínica del psicoanálisis apunta al ser", dice Lacan. Con ello, indica que la estrategia analítica es la palabra, pero ella no es su fin último, sino la vía para develar el ser. Ese "algo" se muestra un poco en la palabra que se encarna, la que se concreta en acto.

\section{ORIGEN LIBIDINAL DE LA JUSTICIA Y LA ÉTICA DISTRIBUTIVA}

La justicia, lejos de ser un "valor" de la voluntad o inducido en la buena enseñanza, surge a partir de las exigencias de satisfacción. En su indagación sobre los colectivos, Freud observa que el niño pequeño cuando añora a la madre, no se calma a la vista de un otro cualquiera, muy al contrario se angustia más al ver un extraño, y durante un largo periodo no manifiesta ningún 'instinto gregario':
Este [el instinto gregario] se forma únicamente cuando los muchachos son muchos en la misma casa, y a partir de su relación con los padres; y se forma en verdad, como reacción frente a la envidia incipiente con que el niño mayor recibe al más pequeño. Aquel, por celos, querría sin duda desalojar al recién llegado, mantenerlo lejos de los padres y expropiarle todos sus derechos; pero en vista de que este niño ---como todos los que vienen después--- es amado por los padres de igual modo, y por la imposibilidad de perseverar en su actitud hostil sin perjudicarse, es compelido a identificarse con los otros niños, y así se forma en la masa infantil un sentimiento de masa y comunidad. La primera exigencia de esa formación reactiva es la de la justicia, el trato igual para todos ${ }^{7}$.

Esto contradice la justicia como fruto de bondad espontánea. El juicio del rey Salomón muestra el carácter egoísta de los impulsos primarios que claman justicia -los de la madre del niño muerto-. Más adelante, como superación de la envidia que clama justicia, se origina el espíritu comunitario:

Ninguno debe querer destacarse, todos tienen que ser iguales y poseer lo mismo. La justicia social quiere decir que uno se niega muchas cosas para que también los otros deban renunciar a ellas o, lo que es lo mismo, puedan exigirlas. Esta exigencia de igualdad es la raíz de la conciencia moral social y del sentimiento de deber ${ }^{8}$.

Entonces, los motores subyacentes al nacimiento de la moral social son de un lado, la búsqueda de una satisfacción amorosa por el conductor de la masa, ya sean padres, jefe, gobernante o Dios $y$, de otro lado, la transformación de los celos: "El sentimiento social descansa, pues, en el cambio de un sentimiento primero hostil en una ligazón de cuño positivo, de la índole de una identificación" ${ }^{\prime \prime}$.

4 Etimológicamente, la palabra "persona" proviene del latín persona, que significa máscara de actor, personaje teatral.

5 El francés diferencia entre la designación del yo imaginario: moi, y el sujeto: je, que en español no es posible.

6 Palabra verdadera en tanto apunta a develar el ser, en tanto se encarna, se hace acto. Es notable que el filósofo del ser haya coincidido en señalar la palabra como el camino para entender por estar ahí nuestro lugar. Para más amplitud: Cf. Heidegger, M. (1976) "Le chemin vers la parole", en Acheminement vers la parole, París. Gallimard, p. 242.

7 Freud, S. (1982) "Psicología de las masas y análisis del yo" (1921), Capítulo IX El instinto gregario, en Obras Completas, Buenos Aires: Amorrortu editores, pp. 113 a 114.

8 lbíd. p. 114.

9 lbíd., p. 115. 
De esa identificación resultante depende el impulso del niño a entrar en comunidad, sin embargo, no logra esa identificación sin el concurso del "tercero" que provee la satisfacción y ante el cual pide igualdad. Esto subraya la importancia del referente simbólico: la Ley, Dios o el Padre. Pero, cuando los referentes simbólicos caen, como sucede actualmente en nuestras sociedades, si por ejemplo, el poder que la tecnología da al niño destituye la autoridad paterna, entonces, la identificación entre los pares no se produce, al menos no en torno a ese padre, sino al ideal que demuestre el poder de satisfacer y por el cual valga la pena competir.

Este mecanismo estructural ocurre (con variaciones) en cualquier cultura, se compite por objetos de consumo y gadgets, que sustituyen los ideales, minan los lazos sociales y la conciencia moral.

\section{CONSECUENCIAS SOCIALES DE LA CAÍDA DEL IDEAL}

El lugar del referente simbólico, como ideal, es crucial para la unión de los sujetos, no importa qué lo ocupe. Puede ser "alguien", pero también puede ser "algo": igual un líder que un libro sagrado, el dinero o la droga ilícita que congrega mafias, etc. Lo peligroso es que hoy son más creíbles éstos últimos, porque proveen más poder de forma más rápida.

Como muestra el sociólogo Alain Touraine, la sociedad contemporánea se desmoderniza ${ }^{10}$ y oscila entre la tendencia a la atomización del sujeto suelto, aislado e incapaz de proyectos colectivos y, de otro lado, la identificación fanática, las sectas y la alienación de masas. Unos abandonan el deber que giraba en torno a la autoridad o a Dios, otros borran su singularidad identificados por alguna fe fanática y para no sentirse solos.

La certeza en el poder humano deriva de la amalgama entre ciencia y capitalismo salvaje, la cual genera el borramiento de la verdad, porque para el sujeto de la ciencia, magia y religión no son sino sombras, aunque tienen importancia para el sujeto sufriente o para el que enfrenta dilemas éticos, es decir, para el sujeto responsable. La posición de la religión invita a confiar la verdad a Dios, es decir, como causa final; mientras para la ciencia moderna la verdad aparece sólo como causa formal, como dice Lacan:

...la fecundidad prodigiosa de nuestra ciencia debe interrogarse en relación con ese aspecto en el que se sostendría la ciencia, que de la verdad como causa no querría saber nada. Se reconoce aquí la fórmula que doy de la Verwerfung o preclusión [...] la verdad como causa en la ciencia debe reconocerse bajo el aspecto de la causa formal. ${ }^{.1}$

La Verwerfung es el mecanismo de la psicosis, lo que explica que afecte a varios científicos y que tenga efectos psicotizantes sobre la sociedad. La ciencia, a diferencia de lo que ocurre en la magia o en la religión, comunica el saber, pero sus comunicaciones tienen el sello del esfuerzo por eliminar al sujeto, por desconocerlo en su singularidad, en su ser (su verdad).

El psicoanálisis no se apasiona por la verdad porque ella es siempre singular, pero no la niega. Su objetivo clínico es lograr que el saber del hablante sea proferido desde el lugar de su verdad, es decir, que asuma los límites de lo que es posible decir, que admita la existencia de lo imposible, puesto que lo imposible duele y de ello se prefiere culpar siempre a otros. Entonces, debido a que hacer existir su ser con palabras es imposible, la alternativa que queda al sujeto para realizar su singularidad es el acto ético, puesto que su ser lo decide.

\section{LOREAL INELIMINABLE}

Lacan llamó "real" a lo imposible de recubrir por el significante, lo real es la organización desconocida del mundo y de sí mismo. Ese real organizado, vuelve siempre, asalta y duele, porque es irreductible y revela la impotencia del 
hombre, de esa verdad la ciencia no desea saber nada. La noción de progreso surge del imperativo de solucionar todo con el poder de la ciencia y el dinero. Pero ni los lirios ("que ni hilan ni tejen") le deben sus colores a la ciencia, ni los mercaderes merecen ocupar el lugar de lo sagrado, como anunció Jesús.

Si bien la ciencia es eficiente para tramitar algunos efectos de lo real, ella no admite que sea ineliminable, ni que su misma eficacia es fuente de nuevas aporías reales, verbigracia: un nuevo y más potente antibiótico crea nuevas resistencias en las bacterias; cada material más resistente y liviano, introduce nuevos desechos y más trastornos ecológicos; cada avance en el control sobre la vida, genera más ansias de poder sobre el prójimo y los seres vivos; cada nueva arma reactiva la retaliación; cada confort cotidiano nos hace más ignorantes y dependientes ante la tecnología, etc. En suma, la falta del mundo es lo único garantizado: la organización de la vida cotidiana y el control social tienen por contrapartida otras formas de segregación, fanatismo, biopolítica o fascismo.

Eludiendo esta falta, la ciencia -como el sicótico- sostiene la certeza que impide creer, puesto que sólo es posible creer en aquello que no es seguro. Los sicóticos, dice Lacan: "no creen en el Otro [simbólico], ellos están seguros de que la cosa sabe"12. La creencia no es siempre fe religiosa, podemos creer en la función del Otro simbólico y que el hombre no es el único que sabe, pues también en lo real funciona un saber acéfalo (la replicación del ADN, por ejemplo). Para algunos, Dios ocupa ese lugar; para otros, simplemente existe el significante funcionando en lo real. De todos modos, del lugar de la creencia vacío o no- depende el lazo social. Cuestionar en qué se cree y cómo creemos es de todo interés social, pues la forma de creer y su lugar, prefiguran la estructura del lazo social que cada cual promueve.

\section{ELSER REAL DELSUJETO Y EL LAZO SOCIAL}

La reticencia $\left(\right.$ reti-sens, $\left.{ }^{13}\right)$ del ser al significante se explica porque no son del mismo registro, la palabra (simbólica) representa algo que ella no es, no atrapa el ser (real).

Lacan ubica al inconsciente como lo social mismo cuando dice: "el inconsciente es aquella parte del discurso concreto, en cuanto transindividual, que falta a la disposición del sujeto para establecer la continuidad de su discurso conciente ${ }^{114}$. Quiere decir, que la falta en lo inconsciente es aquello inconcebible, que para otros sujetos no lo es. No porque ellos sí estén completos, sino porque sus faltas son otras, cada sujeto padece una distinta. Lo que permite decir que podemos identificarnos porque todos padecemos de una de ellas, en eso somos iguales, pero a la vez no lo somos, precisamente, porque nos diferenciamos radicalmente en la calidad de la falta. Lo que falta en el lenguaje implica que ni siquiera él, el Otro del significante está completo.

Entonces, la solidaridad o la justicia, no pueden esperarse del voluntarismo, sino del juicio que permita cernir la lógica que nos liga, no como satisfacción de tener, pues no por nada Jesús arrojó a latigazos a los mercaderes del templo, repudió que el mercado ocupara el lugar de la adoración.

Opuesto al tener, está el ser, por eso la justicia comporta dos niveles:

1. El reclamo de equidad: Además de lo ya explicado sobre el origen de la distribución de bienes; a todos nos afecta la falta de la palabra, que no dice nuestro ser, entonces creemos que existe una injusticia con nuestro ser, al no haber sido inscrito en la ley o en alguna parte del lenguaje. La lucha entre las diferencias está motivada por este reclamo, que no reconoce la falta como estructural.

12 Lacan, J. (1964- 1965) Les problèmes cruciaux pour la psychanalyse, Publication hors commerce. Ducument interne à l'Association freudienne internationale et destiné à ses membres, p. 363.

13 El neologismo es de Lacan e introduce un equívoco homófono entre reticence y reti-sens, "reti-sentido", señalando que el ser no es dicho nunca por el sentido de las palabras.

14 J. Lacan. "Función y campo de la palabra y el lenguaje en psicoanálisis", en Escritos 7, Barcelona, Siglo XXI editores, (1985) pág. 248. 
2. El juicio que acepta la alteridad: Pero si en su búsqueda de verdad, el sujeto reconoce que la palabra no puede sancionar su ser porque es radicalmente otro (otra cosa que no es lenguaje), entenderá por qué él es extraño y lo son para él los demás sujetos, puesto que el ser de cada cual es distinto. Reconocer esta imposibilidad no complace, pero es verdad para el juicio. Además, al compartir esa radical alteridad con los otros, la sumisión al lenguaje ahí toca límite. Ese ser inefable separa al sujeto de los demás por su diferencia, pero lo liga en la alteridad compartida, es decir, al ser afectados por la misma insuficiencia del significante.

Si la palabra no dice al ser, las leyes, las normas (que son producidas en el lenguaje) tampoco alcanzan. Por eso es imprescindible el juicio ético. La justicia antes que nada es la de reconocer la existencia del ser, del otro que somos todos para la cultura en tanto ésta es lenguaje.

\section{La justicia ética considera la alteridad y ésta renueva la sociedad}

Para la actualidad colombiana es imprescindible la justicia, tanto la distributiva, que es un derecho legal, como ese otro tipo, más elevado que es la justicia ética.

Quienes han venido trabajando por la reparación a las víctimas han encontrado una buena propuesta, que resumo así: No sólo se han violado los derechos básicos, como la vida, la pertenencia a un territorio y la posesión de los bienes por el trabajo, se ha intentado eliminar lo otro, lo extraño al propio pensar: si se han asesinado sindicalistas es por quienes no pueden admitir que haya sindicatos; si se han matado periodistas, es por aquellos a quienes repugnan sus comunicados; si se han desaparecido docentes, es porque hay a quienes extraña la libertad de cátedra, etc.

Si se atentó contra lo otro, lo inadmisible, lo impensable, entonces, para que la justicia sea ética, la existencia del otro, de lo extraño, de lo impensable tendría que ser preservada. Ya no se puede devolver la vida biológica a quienes la perdieron, pero puede retribuirse a su vida de sujeto, su causa, que sigue en riesgo. Por lo tanto, la justicia que considere la alteridad, tendría que ir más allá de la equidad que sería legal, debe compensar al sujeto, del cual resta su causa.

Si se mató a un sindicalista, la reparación será dar retribuciones, garantías y nuevo apoyo legal a "lo sindical"; si se asesinó a un periodista que hacía denuncias de corruptos, esta causa debe ser privilegiada y protegida por la sociedad; si un docente fue muerto por su enseñanza, se deben aprobar nuevas formas de estímulo y premio a los catedráticos libre pensadores, etc.

Quizás sea preciso reflexionar aún mucho más para crear nuevas alternativas de justicia que terminen este sangriento conflicto. Lo cierto es que esta sensata propuesta de reparación da cuenta de cómo la justicia se aproxima a la ética cuando, yendo más allá de la distribución de los bienes, apunta a preservar la vida del sujeto: lo que llamamos su causa, su alteridad, que es también lo otro inadmisible.

No por azar Jesús, Gandhi, Antígona, Jean Valjean y tantos otros sujetos éticos defendían una causa "perdida", pues sólo por ello, jamás puede aceptarse la alteridad radical, que renueva al lazo que nos liga. Creo que renovar la forma de relacionarnos es lo que necesita este país para que alguna vez haya justicia, la cual no surge espontáneamente, primero la alteridad, porque si el sujeto no la reconoce en sí mismo, ¿̇cómo podría aprehenderla en los otros? 